\title{
Papers
}

\section{Use of hospitals, physician visits, and hospice care during last six months of life among cohorts loyal to highly respected hospitals in the United States}

\author{
John E Wennberg, Elliott S Fisher, Thérèse A Stukel, Jonathan S Skinner, Sandra M Sharp, Kristen K Bronner
}

\begin{abstract}
Objective To evaluate the use of healthcare resources during the last six months of life among patients of US hospitals with strong reputations for high quality care in managing chronic illness.

Design Retrospective cohort study based on claims data from the US Medicare programme.

Participants Cohorts receiving most of their hospital care from 77 hospitals that appeared on the 2001 US News and World Report "best hospitals" list for heart and pulmonary disease, cancer, and geriatric services.

Main outcome measures Use of healthcare resources in the last six months of life: number of days spent in hospital and in intensive care units; number of physician visits; percentage of patients seeing 10 or more physicians; percentage enrolled in hospice. Terminal care: percentage of deaths occurring in hospital; percentage of deaths occurring in association with a stay in an intensive care unit.

Results Extensive variation in each measure existed among the 77 hospital cohorts. Days in hospital per decedent ranged from 9.4 to 27.1 (interquartile range 11.6-16.1); days in intensive care units ranged from 1.6 to 9.5 (2.6-4.5); number of physician visits ranged from 17.6 to 76.2 (25.5-39.5); percentage of patients seeing 10 or more physicians ranged from $16.9 \%$ to $58.5 \%$ (29.4-43.4\%); and hospice enrolment ranged from $10.8 \%$ to $43.8 \%$ (22.0-32.0\%). The percentage of deaths occurring in hospital ranged from $15.9 \%$ to $55.6 \%(35.4-43.1 \%)$, and the percentage of deaths associated with a stay in intensive care ranged from $8.4 \%$ to $36.8 \%(20.2-27.1 \%)$.

Conclusion Striking variation exists in the utilisation of end of life care among US medical centres with strong national reputations for clinical care.
\end{abstract}

\section{Introduction}

The frequency of use of hospitals, intensive care units, and physician visits among patients with chronic illness varies extensively across hospital regions in the United States, including regions served by well known academic medical centres. The variations are unrelated to population based measures of need but are closely associated with the per capita supply of hospital beds and physicians. ${ }^{1-4}$ The variations in frequency of use of these "supply sensitive" services during the last six months of life are particularly striking. ${ }^{1}$ These variations are of concern because they do not seem to reflect patients' preferences or rates of illness. Moreover, patients with chronic illnesses who live in regions with high rates of use do not seem to have better health outcomes. ${ }^{5-7}$ For these reasons, we have argued that the research agenda for academic medical centres should give high priority to comparative studies of their own patterns of practice with the goal of rationalising the management of chronically ill patients and answering questions about how many hospital beds and physicians are needed to provide optimal care. ${ }^{58}$ An important first step is to obtain population based performance measures specific to academic medical centres. In this paper, we document extensive variations in end of life care among cohorts of patients enrolled in Medicare who receive most of their inpatient care at well known academic medical centres in the United States.

\section{Methods}

\section{Selection of cohorts}

Hospital specific utilisation measures are feasible because patients, particularly those with chronic illness, tend to receive most of their inpatient care from a given hospital. ${ }^{4}$ For this study, we identified those patients who received most of their inpatient care during the last two years of their lives from a hospital that appeared on the 2001 US News and World Report list of "America's best hospitals" for geriatric care and for the treatment of three common chronic illnesses: heart disease, cancer, and pulmonary disease. ${ }^{9}$ By using Medicare's hospital admission files for all Medicare patients who died in 1999-2000, we assigned decedents to the hospital used most often during the last two years of life. In the case of a tie, assignment was to the last hospital used before death. We included only decedents who had been continuously enrolled in traditional Medicare during that period. We generated utilisation measures for the cohorts assigned to the selected hospitals. The databases used to generate performance measures included a $100 \%$ sample of hospital admissions and hospice enrolments and a 20\% sample of claims from physicians and laboratories.

\section{Outcome measures}

The measures of utilisation during the last six months of life included the number of days spent in hospital ("hospital days"), the number of days spent in intensive care units ("ICU days"), the number of physician visits, the percentage of patients seeing 10 or more physicians, and the percentage of patients enrolled in a hospice. Measures of intensity of terminal care included the percentage of deaths occurring in hospital and the percentage of deaths involving a stay in an intensive care unit. 


\section{Statistical analysis}

We used Iezzoni's approach to coding chronic conditions. ${ }^{10} \mathrm{On}$ the basis of diagnoses that appeared on the record of the last hospital admission, we determined the presence of up to 11 chronic conditions and used these conditions to adjust for differences among cohorts in underlying rates of disease. The denominator for calculating utilisation rates in the last six months of life was the full six months of observation before death. We calculated crude hospital specific rates by using the number of cohort members assigned to the hospital as the denominator.

In this paper, we have adjusted the hospital and visit rates directly for age, sex, race, and illness by using overdispersed Poisson regression models. ${ }^{11}$ In the regression models, the dependent variable was the total event count per decedent and the independent variables were indicator variables for the study hospitals and for age (five categories), sex, race (non-black, black), and chronic condition (11 dichotomous variables). We centred all covariates about the population mean so that the rates reflect an average member of the study population. As patients were nested within hospitals, we used the overdispersion parameter to adjust the confidence intervals for correlations among outcomes of patients within the same cohort. We used overdispersed logistic regression to analyse events that could occur only once (for example, enrolment in a hospice). To transform the hospital specific regression coefficients into a directly standardised rate on the original scale, we exponentiated and calibrated them so that they had the same overall mean as the crude hospital specific rates.

We evaluated relations between hospital specific rates by using product-moment correlation. We used the coefficient of variation and interquartile and extremal range ratios to compare the degree of variation among utilisation measures. We also compared variation graphically by displaying the directly standardised rate for each hospital, expressed as a ratio to the mean rate among the 77 hospital cohorts.

\section{Final sample of hospital specific cohorts}

Ninety two acute general hospitals appeared one or more times on the US News and World Report list for 2001. We excluded hospitals with fewer than 100 decedents with data for physician claims, leaving 77 hospital cohorts. In keeping with the principles of population based epidemiology, performance measures reflect the total amount of care received, regardless of where or by whom care was provided. However, as patient loyalty (defined as percentage of all days in hospital that occurred in the assigned hospital) tended to be strong, the measures primarily reflect services undertaken by providers affiliated with the medical centre to which the patients were assigned. Among the 77 hospital specific cohorts, patient loyalty, measured over the two years before death, ranged from $64.6 \%$ to $91.9 \%$, with a median of $82.5 \%$ and a mean of $81.4 \%$.

\section{Results}

Table 1 shows the characteristics of the study population. Of the 115089 patients, 98415 (85\%) were chronically ill, many with two or more conditions. The intensity of care during the last six months of life and at the time of death varied substantially. The figure shows the standardised utilisation ratios and statistical measures of variation among the 77 hospital cohorts. Among the 77 hospital cohorts, the average number of days spent in hospital during the last six months of life was more than 27 days - almost a month-in the highest ranked cohort and fewer than 10 days in the lowest ranked cohort. Average ICU days var-
Table 1 IIIness and demographic characteristics among patients assigned to 77 hospital cohorts. Values are numbers (percentages)

\begin{tabular}{lc} 
Characteristic & Patients (n=115 089) \\
\hline Chronic conditions: & \\
\hline Cancer: solid tumours & $31764(27.6)$ \\
\hline Lymphomas and leukaemias & $6279(5.5)$ \\
\hline AlDS & $103(0.1)$ \\
\hline Chronic pulmonary disease & $964(22.5)$ \\
\hline Coronary artery disease & $931(8.6)$ \\
\hline Congestive heart failure & $3754(32.7)$ \\
\hline Peripheral vascular disease & $558(5.2)$ \\
\hline Severe chronic liver disease & $2317(2.0)$ \\
\hline Diabetes with end organ damage & $2902(2.5)$ \\
\hline Chronic renal failure & $6809(5.9)$ \\
\hline Nutritional deficiencies & $12068(10.5)$ \\
\hline Dementia & $17062(14.8)$ \\
\hline Functional impairment & $3040(2.6)$ \\
\hline No of chronic conditions: & $17674(15.4)$ \\
\hline None & $49568(43.1)$ \\
\hline 1 only & $33914(29.5)$ \\
\hline 2 only & $11656(10.1)$ \\
\hline 3 only & $2277(2.0)$ \\
\hline$\geq 4$ & \\
\hline Demographic characteristics: & $12912(11.2)$ \\
\hline Age 65-69 & $19811(17.2)$ \\
\hline Age 70-74 & $23545(20.5)$ \\
\hline Age 75-79 & $22995(20.0)$ \\
\hline Age 80-84 & $35826(31.1)$ \\
\hline Age $\geq 85$ & $52313(45.5)$ \\
\hline Male & $62776(54.5)$ \\
\hline Female & $17349(84.9)$ \\
\hline Non-black & \\
\hline & \\
\hline
\end{tabular}

ied by a factor of six, from 1.6 to 9.5 days per person; physician visits varied by a factor of four, from less than 18 to more than 76 visits per decedent. The propensity to use multiple physicians varied from less than $17 \%$ of patients seeing 10 or more physicians in the last six months of life to more than $58 \%$ of patients. The percentage of deaths occurring in hospital ranged from less than $16 \%$ to more than $55 \%$; deaths associated with a stay in an intensive care unit varied from less than $9 \%$ to more than $36 \%$. Enrolment in a hospice varied among the cohorts from less than $11 \%$ of decedents to more than $43 \%$.

Table 2 examines the intensity of care during the last six months for cohorts loyal to major teaching hospitals located in metropolitan regions with two or more major teaching hospitals. They are ranked according to the (unweighted) average number of patient days per decedent. By this measure, the hospitals located in Manhattan provided the most care. Other regions with high hospital day rates included Los Angeles, Philadelphia, and Washington, DC. Patient cohorts loyal to the teaching hospitals in these regions also tended to have a higher frequency of physician visits, and a higher proportion saw 10 or more physicians. However, the use of intensive care units varied: the rates were high among the listed teaching hospital cohorts in Los Angeles, low in Washington, DC, and varied substantially according to specific hospital cohorts in Philadelphia and New York. Cohorts in Boston and St Louis exhibited considerable within area variation in hospital days and ICU days. By contrast, those in Minneapolis and San Francisco had low rates on all four measures of intensity of care in the last six months of life.

The observed variation could have been generated by substitution between hospital use, physician visits, and hospice care. Enrolment in a hospice was inversely correlated with hospital 


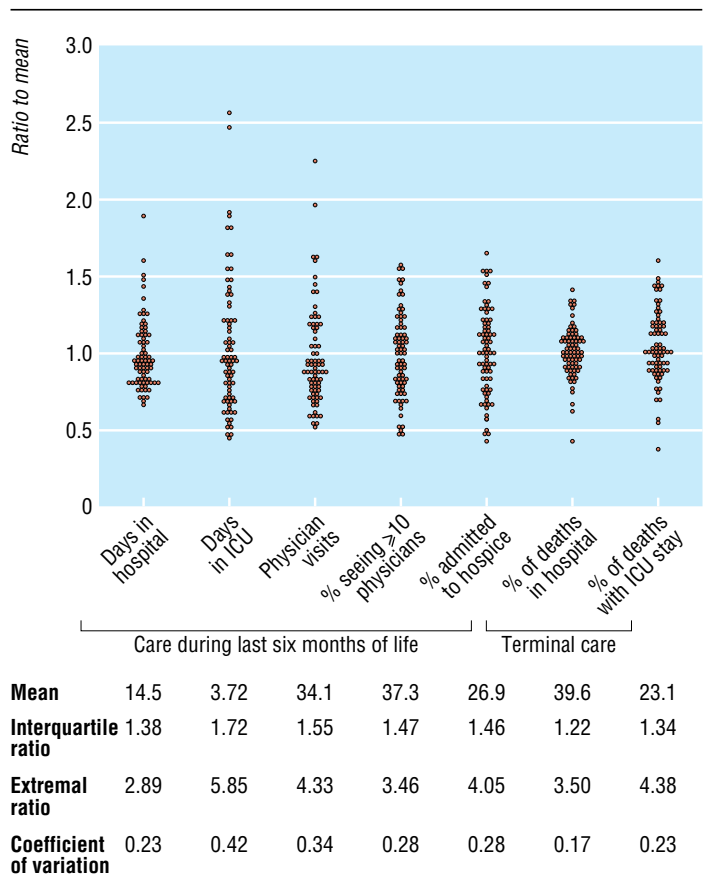

Distribution of rates and statistical measures of variation for end of life care among 77 cohorts assigned to hospitals with national reputations for high quality. ICU=intensive care unit

days in the last six months of life $(r=-0.41 ; \mathrm{P}<0.0002)$, the chance of dying in a hospital $(r=-0.51 ; \mathrm{P}<0.0001)$, and the percentage of deaths occurring in association with a stay in the intensive care unit $(r=-0.28 ; \mathrm{P}=0.012)$. However, the percentage enrolled in a hospice was not correlated significantly $(\mathrm{P}>0.05)$ with fewer physician visits, seeing 10 or more physicians, or ICU days in the last six months of life. We found a strong positive correlation between the number of days spent in hospital and the number of physician visits within the last six months of life $(r=0.77 ; \mathrm{P}<0.0001)$.

\section{Discussion}

Academic medical centres in the United States with reputations for excellence differed dramatically in the care they provided to patients during the last six months of life. For example, patient cohorts loyal to the University of California Medical Center in San Francisco had, on average, 27 physician visits, with 30\% seeing 10 or more physicians and spending an average of 11.5 days in hospital. For the New York University hospital cohort, average physician visits were 76, nearly triple the frequency in San Francisco, with $57 \%$ seeing 10 or more physicians and spending an average of 27.1 days in hospital. The context of terminal care also varied. For example, the chance that death was associated with a stay in an intensive care unit was 1.84 times greater for patients loyal to Cedars-Sinai Hospital in Los Angeles (36.8\%) than for patients loyal to New York's Mt Sinai Hospital (21.1\%).

\section{What explains such variation?}

Among regions, a direct relation exists between supply and utilisation of services. The frequency of use of physician services is strongly associated with the local workforce supply, ${ }^{12}{ }^{13}$ and bed supply "explains" more than half of the variation in hospital admission rates for medical conditions. ${ }^{1}$ The effect of bed supply is to influence the threshold for admitting patients with chronic illnesses such as congestive heart failure, chronic pulmonary obstructive disease, and cancer. ${ }^{2-4}{ }^{14}$ Finally, physicians have been shown to adapt their decisions about admission and discharge to the availability of intensive care unit beds, admitting more patients with lower severity of illness and extending their length of stay when more beds are available. ${ }^{15}{ }^{16}$ In the light of this evidence, the likely explanation for the variations in acute hospital care and physician visits is variation in bed and workforce capacity relative to the size of population loyal to the 77 hospitals.

The key question is whether greater frequency of physician visits and hospital care for chronically ill patients (many of whom are in the sample of decedents) results in better health outcomes. Using a variety of measures, two randomised trials of elderly patients from the US Veterans Affairs healthcare system found that more frequent office visits and more intensive primary care were associated with increased use of the hospital but no improvement in health or function. ${ }^{17}{ }^{18}$ Both studies found that more frequent office based visits were associated with a non-significant increase in mortality. Recently, we compared practice patterns and health outcomes across regions of the United States that were similar in baseline health status but that differed by $60 \%$ in overall utilisation of services. ${ }^{6}$ Greater frequency of use was associated with worse outcomes: quality and access to care were slightly worse in higher spending regions, and mortality was between $2 \%$ and $5 \%$ higher, suggesting that overuse of supply sensitive services was leading to harm, possibly because greater use of hospital and specialist care exposes populations to greater risks of medical errors. ${ }^{7}$

\section{Limitations of the study}

Our study has limitations. Firstly, the focus was on acute hospital care and frequency of physician visits. With the exception of hospice care, we were unable to evaluate the contribution of community care services such as home health agencies or nursing homes. Interestingly, whereas hospice enrolment varied substantially among the 77 cohorts, we did not find that increased use of hospice led to less use of intensive care units or physician visits during the last six months of life. It was, however, associated with fewer deaths in hospital and, to a lesser degree, with a decrease in the chance that death was associated with a stay in an intensive care unit. We had no information on patients' or caregivers' preferences for end of life care or on their satisfaction with the services provided, the effectiveness of pain control, or the degree of emotional or physical support provided by each healthcare system. However, the SUPPORT study documented deficiencies in these aspects of care across five major medical centres (two of which were included in our study) and showed that the differences in hospital care were due neither to case mix nor to patients' preferences. ${ }^{19}$ Indeed, patients' stated preferences to avoid deaths in hospital were commonly unfulfilled, whereas the local bed supply was correlated with probability of dying in the hospital.

Secondly, the "follow back" design means that we excluded patients who did not experience at least one hospital admission during their last two years of life. Among the 306 hospital referral regions in the Dartmouth Atlas of Health Care, the percentage of deaths in 1999-2000 without any hospital admission within two years of death (and hence unassigned to any hospital) ranged from $8 \%$ to $30 \%$. Thus, we based end of life hospital admission rates on a denominator that is too small. Assuming that the unassigned deaths in the region are assigned in proportion to the total number of deaths at each hospital would suggest adjustment of each end of life variable by $1 /(1-x)$, where $\mathrm{x}$ is the fraction of "unassigned" deaths. Adjusting our variables in this way had little impact on our results, and if anything tended 
Table 2 Age, sex, race, and illness adjusted rates (95\% confidence intervals) for hospital days, days in intensive care, and physician visits and percentage seeing 10 or more physicians during last six months of life among patient cohorts loyal to selected academic medical centres by region of location

\begin{tabular}{|c|c|c|c|c|}
\hline Hospital by region* & Hospital days per decedent & ICU days per decedent & Physician visits per decedent & $\%$ seeing $\geq \mathbf{1 0}$ physicians \\
\hline \multicolumn{5}{|l|}{ New York (23.8) } \\
\hline Mount Sinai Hospital & 22.8 (22.1 to 23.5 ) & 2.8 (2.6 to 3.0 ) & 53.9 (50.6 to 57.4 ) & 58.5 (51.8 to 66.0 ) \\
\hline New York Presbyterian Hospital & 21.6 (21.0 to 22.2$)$ & $4.5(4.2$ to 4.7$)$ & 40.3 (37.9 to 42.8$)$ & 37.7 (33.2 to 42.7$)$ \\
\hline $\begin{array}{l}\text { NYU Medical Center-University } \\
\text { Hospital }\end{array}$ & 27.1 (26.1 to 28.1) & 6.7 (6.4 to 7.2$)$ & 76.2 (71.3 to 81.3) & 57.1 (49.0 to 66.4$)$ \\
\hline \multicolumn{5}{|l|}{ Los Angeles (18.7) } \\
\hline UCLA Medical Center & $16.1(15.2$ to 17.1$)$ & $9.2(8.6$ to 9.8$)$ & 43.9 (39.7 to 48.5$)$ & $50.9(42.2$ to 61.4$)$ \\
\hline Cedars-Sinai Medical Center & $21.3(20.6$ to 22.0$)$ & $7.0(6.7$ to 7.4$)$ & $66.2(62.7$ to 69.9$)$ & 48.2 (42.5 to 54.8$)$ \\
\hline \multicolumn{5}{|l|}{ Washington, DC (18.4) } \\
\hline Georgetown University Hospital & 18.5 (17.3 to 19.8$)$ & 3.6 (3.1 to 4.1$)$ & $43.0(37.2$ to 49.7$)$ & 55.1 (42.6 to 71.3$)$ \\
\hline Washington Hospital Center & $18.2(17.4$ to 19.0$)$ & 3.0 (2.7 to 3.2$)$ & $37.0(33.5$ to 40.9$)$ & 39.4 (32.5 to 47.9$)$ \\
\hline \multicolumn{5}{|l|}{ Philadelphia (18.3) } \\
\hline $\begin{array}{l}\text { Hospital of the University of } \\
\text { Pennsylvania }\end{array}$ & $17.2(16.2$ to 18.2$)$ & 3.8 (3.4 to 4.2$)$ & $40.3(35.7$ to 45.5$)$ & 44.7 (35.4 to 56.4$)$ \\
\hline $\begin{array}{l}\text { Thomas Jefferson University } \\
\text { Hospital }\end{array}$ & 19.4 (18.6 to 20.2$)$ & $9.5(9.1$ to 10.0$)$ & $55.0(50.8$ to 59.4$)$ & 53.7 (45.8 to 62.8$)$ \\
\hline \multicolumn{5}{|l|}{ Baltimore (16.3) } \\
\hline Johns Hopkins Hospital & $16.1(15.2$ to 17.0$)$ & $3.2(2.9$ to 3.5$)$ & 28.1 (24.9 to 31.7$)$ & 36.7 (29.6 to 45.4$)$ \\
\hline Francis Scott Key Medical Center & 16.5 (15.7 to 17.5$)$ & $5.7(5.3$ to 6.1$)$ & $23.0(20.0$ to 26.5$)$ & $29.4(22.9$ to 37.9$)$ \\
\hline \multicolumn{5}{|l|}{ Chicago (16.1) } \\
\hline University of Chicago Hospital & $13.4(12.6$ to 14.3$)$ & $3.5(3.2$ to 3.9$)$ & $30.2(26.6$ to 34.3$)$ & $41.7(33.5$ to 51.9$)$ \\
\hline $\begin{array}{l}\text { Rush-Presbyterian-St Luke's Medical } \\
\text { Center }\end{array}$ & $17.9(16.9$ to 19.0$)$ & 4.5 (4.1 to 4.9$)$ & 48.9 (44.1 to 54.3$)$ & 35.1 (27.4 to 44.9$)$ \\
\hline $\begin{array}{c}\text { Northwestern Memorial Hospital } \\
\end{array}$ & $17.1(16.3$ to 17.9$)$ & 3.5 (3.2 to 3.8$)$ & $34.9(31.7$ to 38.4$)$ & 40.4 (33.8 to 48.3$)$ \\
\hline \multicolumn{5}{|l|}{ Boston (14.5) } \\
\hline Boston Medical Center & $15.6(14.5$ to 16.8$)$ & $3.9(3.5$ to 4.4$)$ & $31.5(27.0$ to 36.6$)$ & $47.8(37.2$ to 61.4$)$ \\
\hline Massachusetts General Hospital & 16.5 (15.8 to 17.1$)$ & 2.5 (2.3 to 2.7$)$ & 38.8 (35.8 to 41.9$)$ & 46.2 (40.0 to 53.3$)$ \\
\hline $\begin{array}{l}\text { Beth Israel Deaconess Medical } \\
\text { Center }\end{array}$ & $12.2(11.6$ to 12.8$)$ & $2.4(2.2$ to 2.6$)$ & 29.2 (26.5 to 32.2) & $34.3(28.7$ to 41.1$)$ \\
\hline Brigham and Womens Hospital & $13.9(13.1$ to 14.7$)$ & $3.2(2.9$ to 3.6$)$ & $31.9(28.3$ to 36.0$)$ & 43.7 (35.6 to 53.6$)$ \\
\hline \multicolumn{5}{|l|}{ St Louis (14.5) } \\
\hline Barnes-Jewish Hospital & 16.1 (15.6 to 16.7$)$ & $4.4(4.2$ to 4.7$)$ & 29.5 (27.3 to 31.9$)$ & $30.9(26.5$ to 36.0$)$ \\
\hline St Louis University Hospital & $12.9(12.0$ to 13.9$)$ & $6.1(5.6$ to 6.7$)$ & $31.5(27.0$ to 36.7$)$ & 38.1 (28.7 to 50.4$)$ \\
\hline \multicolumn{5}{|l|}{ Cleveland (13.0) } \\
\hline University Hospitals of Cleveland & $12.5(11.9$ to 13.2$)$ & $2.4(2.2$ to 2.6$)$ & $26.0(23.3$ to 29.0$)$ & 30.5 (25.0 to 37.4$)$ \\
\hline $\begin{array}{l}\text { Cleveland Clinic } \\
\end{array}$ & 13.4 (12.8 to 14.1$)$ & 3.0 (2.8 to 3.3$)$ & 30.9 (28.2 to 33.9$)$ & 45.9 (39.5 to 53.4$)$ \\
\hline \multicolumn{5}{|l|}{ Minneapolis (11.4) } \\
\hline Hennepin County Medical Center & $9.6(8.7$ to 10.6$)$ & 4.0 (3.6 to 4.5$)$ & $18.1(14.7$ to 22.4$)$ & 28.3 (20.1 to 39.8$)$ \\
\hline $\begin{array}{c}\text { Fairview-University Medical Center } \\
\end{array}$ & $13.3(12.3$ to 14.4$)$ & $2.3(1.9$ to 2.6$)$ & $23.9(20.0$ to 28.6$)$ & $34.8(25.8$ to 46.9$)$ \\
\hline \multicolumn{5}{|l|}{ San Francisco/Bay Area (10.8) } \\
\hline $\begin{array}{l}\text { University of CA San Francisco } \\
\text { Medical Center }\end{array}$ & 11.5 (10.6 to 12.4$)$ & $2.6(2.3$ to 3.0$)$ & 27.2 (23.0 to 32.2$)$ & $30.3(22.0$ to 41.9$)$ \\
\hline Stanford University Hospital & 10.1 (9.4 to 10.9$)$ & $4.3(4.0$ to 4.7$)$ & 22.6 (19.4 to 26.3$)$ & 23.1 (17.1 to 31.3$)$ \\
\hline
\end{tabular}

Stanford University Hospital

ICU=intensive care unit.

*Regions ranked by unweighted average for patient days among listed hospital cohorts; average given in parenthesis.

to increase rather than decrease dispersion across hospitals. Thirdly, we have underestimated loyalty for medical centres that use affiliated hospitals, because information on affiliation was not available.

\section{Generalisability}

Variations in end of life care among the best hospitals in the United States raise questions about the appropriate role for acute hospital care in the management of chronically ill patients. Patterns of practice during this period of care are highly correlated with variation at other stages in the progression of chronic illness. Thus end of life measures provide a good indicator of how hospitals are treating all patients with chronic illness, not just those near death. ${ }^{6}$ Typically, hospital level comparisons are confounded by differences in case mix across communities. However, all patients in the last six months of life are quite similar with regard to at least one critical case mix adjuster-they are all dead within six months. This allows comparisons of use of hospitals during this period of life, with confidence that regional differences in illness are not an important cause of the variations seen. Although we have found that regions allocating the least resources to patients at the end of life tend to have lower mortality and do better on other measures of quality for all of their patients, ${ }^{7}$ this association needs to be tested in countries where the frequency of acute hospital care and physician visits is less than in the United States. We hope the international research community will focus on learning how to manage chronic illness better and how to provide end of life care determined by the needs and wants of patients and not the capacity of the acute care system. ${ }^{20}$

Contributors: All authors were involved in developing the methods for measuring hospital specific performance. TAS and SMS did the statistical analyses. JEW wrote many drafts of the paper, and all authors contributed to the final draft. JEW is the guarantor.

Funding: Grant support by the Robert Wood Johnson Foundation and the National Institute of Aging (1PO1AG19783-01).

Competing interests: None declared. 


\section{What is already known on this topic}

Population based rates of use of hospitals, intensive care units, and physician visits vary extensively across US regions, particularly during the last six months of life

Population based rates are uncorrelated with illness and patients' preferences but are closely associated with the supply of hospital beds and physicians

The outcomes of care are no better among the cohorts of patients with chronic illness who receive care in regions with higher rates of use of services

\section{What this study adds}

Population based rates of use of hospitals and physician services can be measured among populations loyal to specific hospitals

End of life care varies extensively among patient cohorts who receive most of their care from well known academic medical centres, even among those located in the same region

Hospital specific information opens the opportunity for academic medical centres to participate in studies to improve the quality and efficiency of care

Ethical approval: Not needed.

1 Wennberg JE, Cooper MM, eds. The quality of medical care in the United States: a report on the Medicare program. The Dartmouth atlas of health care 1999. Chicago, IL: American Hospital Association Press, 1999.

2 Wennberg JE, Freeman JL, Culp WJ. Are hospital services rationed in New Haven or over-utilized in Boston? Lancet 1987;i:1185-8.

3 Wennberg JE, Freeman JL, Shelton RM, Bubolz TA. Hospital use and mortality among Medicare beneficiaries in Boston and New Haven. N Engl J Med 1989;321:1168-73.

4 Fisher ES, Wennberg JE, Stukel TA, Sharp SM. Hospital readmission rates for cohorts of Medicare beneficiaries in Boston and New Haven. N Engl Med 1994;331:989-95.

5 Wennberg JE, Fisher ES, Skinner JS. Geography and the debate over Medicare reform. 2002. http://content.healthaffairs.org/cgi/content/full/hlthaff.w2.96v1/DC1 (accessed 4 Mar 2004).
6 Fisher ES, Wennberg DE, Stukel DA, Gottlieb D, Lucas FL, Pinder E. The implications of regional variations in Medicare spending: part 1, utilization of services and the quality of care. Ann Intern Med 2003;138:273-87.

7 Fisher ES, Wennberg DE, Stukel DA, Gottlieb D, Lucas FL, Pinder E. The implications of regional variations in Medicare spending: part 2, health outcomes and satisfaction with care. Ann Intern Med 2003;138:288-98.

8 Wennberg, JE. Unwarranted variations in healthcare delivery: implications for academic medical centres. BMJ 2002;325:961-4.

9 America's best hospitals. US News and World Report 2001;131(3).

10 Iezzoni LI, Heeren T, Foley SM, Daley J, Hughes J, Coffman GA. Chronic conditions and risk of in-hospital death. Health Serv Res 1994;29:435-60.

11 McCullagh P, Nelder JA. Generalized linear models. 2nd ed. New York: Chapman and Hall, 1989.

12 Wennberg J, Gittelsohn A. Small area variations in health care delivery: a populationbased health information system can guide planning and regulatory decision-making. Science 1973;182:1102-8.

13 Welch WP, Miller ME, Welch HG, Fisher ES, Wennberg JE. Geographic variation in expenditures for physicians' services in the United States. N Engl J Med 1993;328:621-7.

14 Fisher ES, Wennberg JE, Stukel TA, Skinner JS, Sharp SM, Freeman JL, et al. Associations among hospital capacity, utilization, and mortality of U.S. Medicare beneficiaries, controlling for sociodemographic factors. Health Serv Res 2000;34:1351-62.

15 Singer DE, Carr PL, Mulley AG, Thibault GE. Rationing intensive care-physician responses to a resource shortage. $N$ Engl J Med 1983;309:1155-60.

16 Strauss MJ, LoGerfo JP, Yeltatzie JA, Temkin N, Hudson LD. Rationing of intensive care Strauss MJ, LoGerfo JP, Yeltatzie JA, Temkin N, Hudson LD. Ra
unit services: an everyday occurrence. JAMA 1986;255:1143-6.

17 Wasson JH, Gaudette C, Whaley F, Sauvigne A, Baribeau P, Welch HG. Telephone care Wasson JH, Gaudette C, Whaley F, Sauvigne A, Baribeau P, Welch HA.
as a substitute for routine clinic follow-up. JAMA 1992;267:1788-93.

18 Weinberger M, Oddone EZ, Henderson WG, for the Veterans Affairs Cooperative Study Group on Primary Care and Hospital Readmission. Does increased access to primary care reduce hospital readmissions? N Engl J Med 1996;334:1441-7.

19 Pritchard RS, Fisher ES, Teno JM, Sharp SM, Reding DJ, Knaus WA, et al. Influence of patient preferences and local health system characteristics on the place of death: study to understand prognoses and preferences for risks and outcomes of treatment. J Am Geriatr Soc 1998;46:1242-50.

20 Schneiderman LJ, Gilmer T, Teetzel HD, Dugan DO, Blustein J, Cranford R, et al. Effect of ethics consultations on nonbeneficial life-sustaining treatments in the intensive care setting: a randomized controlled trial. JAMA 2003;290:1166-72. (Accepted 31 December 2003)

bmj.com 2004;328:607

Center for the Evaluative Clinical Sciences, Dartmouth Medical School, 7251 Strasenburgh, Hanover, NH 03755-3863, USA

John E Wennberg Peggy Y Thomson professor for the evaluative clinical sciences

Sandra M Sharp research associate

Kristen K Bronner research associate

VA Outcomes Group, White River Junction, VT 05001, USA

Elliott S Fisher co-director

Institute for Clinical Evaluative Sciences, Toronto, Canada

Thérèse A Stukel research director

Dartmouth College, Hanover, NH 03755, USA

Jonathan S Skinner John French professor of economics

Correspondence to:J E Wennberg john.wennberg@Dartmouth.edu 